Article

\title{
Food Democracy for All? Developing a Food Hub in the Context of Socio-Economic Deprivation
}

\author{
Sebastian Prost \\ Open Lab, School of Architecture Planning and Landscape, Newcastle University, Newcastle upon Tyne, NE4 5TG, UK; \\ E-Mail: s.prost2@newcastle.ac.uk
}

Submitted: 10 March 2019 | Accepted: 12 July 2019 | Published: 28 October 2019

\begin{abstract}
This article proposes a localised and differentiated understanding of food democracy, or rather a plurality of localised food democracies. Based on the experiences of developing a local food hub in an area of socio-economic deprivation in the UK using a participatory action research (PAR) approach, it presents local responses to three key challenges derived from the literature. It argues that for civic food networks (CFNs) to contribute to a transition towards a food democracy, they need to address challenges of: 1) balancing ethical aspirations for environmental sustainability, social justice, as well as community and individual health; 2) developing the skills required for participation in CFNs; and 3) achieving wider impact on food system transformation beyond niche solutions. The responses, or tactics, presented in this article include flexible ethical standards responding to community needs, accessible participation focusing on relationships rather than skills, and a focus on local impact while striving to collaborate and network with other organisations. It thus frames food democracy as a plurality of approaches to build and replicate CFNs. The article positions PAR with its democratic and localised approach to address real-world problems as uniquely suited to navigate the challenges of CFNs. It also discusses the role of researchers in initiating, facilitating, and shaping such processes of food system democratisation as engaged actors.
\end{abstract}

\section{Keywords}

civic food networks; food democracy; food hubs; participatory action research; social justice; sustainability

\section{Issue}

This article is part of the issue "New Perspectives on Food Democracy" edited by Basil Bornemann (University of Basel, Switzerland) and Sabine Weiland (Université Catholique de Lille, France).

(C) 2019 by the author; licensee Cogitatio (Lisbon, Portugal). This article is licensed under a Creative Commons Attribution 4.0 International License (CC BY).

\section{Introduction}

Civic food networks (CFNs) have emerged as democratic and political initiatives that seek to realise alternatives to the global and corporate food system as well as the unsustainability and injustice associated with the latter (Moragues-Faus \& Marsden, 2017). CFNs aim to practice closer producer-consumer relationships and become spaces of democratic decision-making, empowerment and/or collective action to challenge the wider food system (Bornemann \& Weiland, 2019; Renting, Schermer, \& Rossi, 2012). Food democracy, the conceptual framework underpinning CFNs, envisions "food as a locus of the democratic process" (Lang, 2007, p. 12). For the purpose of this article, I want to highlight three key aspects of food democracy: 1) a strong ethical commitment to en- vironmental sustainability, social justice, as well as individual and community health; 2) democratic governance through active participation of food citizens; 3 ) a whole system perspective aiming to transform the entire food system (Levkoe, 2011).

Using this framing of food democracy, this article presents an empirical study of a CFN in the form of a local food hub in the UK in an area of socio-economic deprivation. Food hubs are commonly characterised as a food supply chain management strategy with a specific ethos, as aggregators and distributors for small food producers to allow better consumer access to local, healthy, or sustainably-grown food (Fischer, Pirog, \& Hamm, 2015). Food hubs have played a critical role in emerging local food systems in the US (Perrett \& Jackson, 2015) and Canada (Stroink \& Nelson, 2013) and can be seen as 
building on earlier community food projects in the UK (McGlone, Dobson, Dowler, \& Nelson, 1999). Drawing on literature from a diverse set of fields, this article takes the debate forward on whether or not food hubs challenge the mainstream corporate food system (Perrett \& Jackson, 2015) and are a driver towards food democracy. By looking in depth at the inception of a food hub, it contributes a discussion of three key challenges that CFNs should be aware of and address if they want to contribute to food system transformation. Based on the findings of this case study, this article also contributes responses, or local 'tactics,' to these challenges and frames food democracy as a plurality of localised and networked actions. I use the term tactics in de Certeau, Giard, and Mayol's (1998) sense not simply as the means to implement a strategy, but as a way of (counter-)acting in an environment defined by the strategies of a powerful system. As such, the tactics discussed in this article refer to creative ways of navigating the neoliberal environment defined by powerful market strategies.

The three challenges relate to and interrogate the aspects of food democracy outlined above, i.e., they point to the ethics of CFNs, their participatory form, and their transformative potential. First, balancing the ethical commitments of food democracy, particularly social justice, environmental sustainability, and community health, in practice paradoxically often means that high quality and locally-sourced food is only accessible for groups with the necessary economic, social, and cultural capital (Bos \& Owen, 2016; Levkoe, 2011). Thus, healthy and sustainable food is reduced to a question of economic access and moral choice (Bradley \& Herrera, 2016). Second, the structure and dynamic of many grassroots CFNs require a certain set of skills, engagement, and a willingness to learn in order to enable participation (Mclvor \& Hale, 2015). Third, the extent to which small initiatives who focus on food itself rather than unjust processes in the food system can actually contribute to system change has been questioned (Guthman, 2011). All three challenges result in practices of CFNs that exclude disadvantaged groups.

This article illustrates how these challenges play out in this particular case study and the local tactics applied in response to them. The study adopts a participatory action research (PAR) approach and methodology. PAR is an iterative process in which the researcher and participants collaborate with equal decision-making power to produce practical responses to the participants' real-life problems (Kindon, Pain, \& Kesby, 2007). As I will outline in detail later, this particular PAR process involved myself and others as researchers, local food suppliers, staff and volunteers of a local community centre, and the local community. The empirical account spans three iterative cycles in this process and highlights the everyday challenges facing CFNs. Following a discussion of these three challenges in the next section, the findings will present the local tactics employed to address or work with them creatively. These include tactics to work flexibly with social justice, sustainability, and health ethics based on sensitivity to the community's needs, in order to 'configure' community participation accessible for all, as well as to form collaborations and coalitions to achieve wider impact. 'Configuring' relates to the different forms engagement and interaction can take, who is included, and in which way control is shared (Vines, Clarke, Wright, McCarthy, \& Olivier, 2013). Concluding, I will discuss these findings in relation to the challenges to CFNs, arguing for a plurality of localised food democracies, as well as positioning PAR as a responsive approach to develop localised and unique solutions while at the same time building collaborations and networks to move the overall ambition of food democracy along.

\section{Literature Review: Challenges of CFNs}

This section critically discusses CFNs, and in particular food hubs, through the conceptual lens of food democracy. In doing so, it draws together a diverse body of literature, including food democracy, food justice, alternative food networks, and food hubs. While acknowledging the spectrum of understandings of what food democracy involves, from liberal value-based food chains to radical system transformation (Levkoe et al., 2018; Lohest, Bauler, Sureau, Mol, \& Achten, 2019; Werkheiser \& Noll, 2014), I point to three key challenges food hubs face in their aim to transform and democratise the food system. To be clear, these challenges are not meant to question the ambitions of food democracy as such, but to highlight some of the practical barriers CFNs are confronted with and theoretical blurs of food democracy.

\subsection{The Challenge of Ethics: Sustainability, Social Justice, and Health}

The first challenge of CFNs concerns their ethical standards and their tendency to produce high quality, often artisanal and expensive food. In a market economy, this food competes with lower-priced food in supermarkets. The idea of ethical consumerism suggests that by 'voting with their fork' consumers will eventually transform the wider food system through their purchasing decisions. This assumption, however, has been heavily critiqued (Lorenzini, 2019): As Guthman (2011) argues, neoliberal incentive-based regulation, in contrast to state regulation, leads to higher prices for organic and local food by design, with those who can afford it being rewarded instead of unhealthy or unjust practices being forbidden. CFNs, therefore, run the risk of reinforcing a twotier system providing expensive, healthy and sustainablysourced food for those who can afford it, and cheap and low-quality food for everyone else (Levkoe, 2011).

Other CFNs focus on providing access to and education about 'good food.' This, however, rarely addresses the causes of inequality, which lie elsewhere. It also ignores that what 'good food' is, is commonly being defined by people in relative privilege (food academics and activists). It thus becomes coded as culturally elite 
and may not resonate with people of colour or workingclass neighbourhoods (Guthman, 2008b). Worse, by reducing eating to questions of access, dietary advice becomes highly morally charged. Such healthism fashions 'healthy' people in contrast to 'unhealthy' and thus immoral others (Davenport \& Mishtal, 2019). In the context of food justice, Bradley and Herrera (2016) therefore call for decolonising white and middle-class activism and research. CFNs should focus on and challenge the unjust processes under which food is produced to avoid turning food activism into civilising missions (Guthman, 2011). Thus, CFNs require sensitivity to the location and context in which they operate and participatory approaches to avoid excluding disadvantaged groups.

\subsection{The Challenge of Participation: Skills and Education}

A second challenge to CFNs is the participation of 'food citizens,' who move beyond their passive roles as consumers or producers (Lyson, 2012). Food citizenship encompasses the right and responsibility to inform, define, and enact one's food preferences and participate actively in food governance (Gómez-Benito \& Lozano, 2014). By participating in CFNs, citizens thus learn not only foodrelated but also democratic skills. Through, for example, group work and collective decision-making, they learn skills in communication and coordination, build social capital, and increase their levels of political knowledge and efficacy (Kneafsey, Owen, Bos, Broughton, \& Lennartsson, 2017; Levkoe, 2006). Indeed, being 'exposed' to alternative forms of food provisioning appears to make people more engaged with their community and more politically active (Carolan, 2017). While this is certainly laudable, there is a risk that, as with other forms of capital, social capital's unequal distribution might be reinforced rather than reduced. For example, many grassroots organisations rely on volunteers and self-exploitation (Tornaghi, 2017) and have organisational practices which exclude and alienate those outside the middle-class (Zitcer, 2015). Moreover, by emphasising individual skills and social capital, this thinking again becomes trapped in a neoliberalist discourse around personal responsibility and initiative and therefore risks being collectively disempowering (Guthman, 2008a; Mclvor \& Hale, 2015). The challenge of participation for CFNs is, therefore, to move from being a 'schoolhouse' for democracy to what Mclvor and Hale (2015) call 'deep democracy.' Instead of focusing on developing skills, CFNs should focus on building relationships. In practice, this means moving away from transactional market models to relational modes which embed food in a cultural and social context.

\subsection{The Challenge of System Transformation: Niche Solutions}

The third challenge concerns the potential of CFNs to influence the wider food system. CFNs are often small and operate with limited resources. While they might care about many issues, they often have to focus on one specific issue in order to be effective, which, in turn, means ignoring others (Hassanein, 2003). Therefore, CFNs often operate in niches. For example, by focusing on local food and environmental sustainability, they tend to neglect issues of social injustices in food production, distribution, and consumption (Allen, 2008; Born \& Purcell, 2006; Mares \& Alkon, 2011). Connelly, Markey, and Roseland (2011) argue that while many food hubs start off wanting to confront root causes and ideologies during the planning phase, it is a challenge to maintain such strong commitment when shifting from planning to implementation, given the economic pressure they experience. Echoing Levkoe's (2011) call for a "whole system approach" to food democracy that includes dimensions of social justice, ecological sustainability, and community health, CFNs need to keep aspiring to and practice all these dimensions equally. But how then can food hubs really make a difference? Reframing this question, Hassanein (2003) sees democracy as the only way forward to bring about real change. To follow a democratic path means that there are no alternatives to incremental change. As such, she calls for a "pragmatic politics of transformation." In practical terms, this means to be willing to compromise. Compromise should, however, not be seen as weakness and surrender, but as a mark of integrity if it moves the cause towards the desired goal.

The three challenges discussed in this sectionethics, participation, and system transformation-are both aspirations and challenges for CFNs under the lens of food democracy. The next section will introduce the PAR project that launched a CFN in the form of a food hub. Following this, the findings from this ongoing process will illustrate the local tactics of the food hub as they respond to the challenges discussed.

\section{Methodology}

After introducing the location and community organisation, this section will discuss the specific PAR approach taken in this case and outline the first three action and reflection cycles as well as accompanying methods of data collection in this ongoing collaboration.

\subsection{Research Context: Meadow Well}

The Meadow Well estate is located in the suburban fringe of the Newcastle upon Tyne metropolitan area in North East England. It is inhabited predominantly by British white working-class and low-income families. Decades of neglect by local authorities resulted in a brief period of violent unrest in the mid-1990s. Despite political commitments, little has changed, and today the estate remains among the most deprived $10 \%$ neighbourhoods in England in terms of education, employment, income, health, and environmental quality (OpenDataCommunities, 2015). While not classified as a 
food desert (having access to a large supermarket within two miles), many residents rely on walking and therefore predominantly access small convenience stores or fast food outlets on the estate. Despite being located immediately next to wealthier seaside towns and Newcastle, social stigma and failed public interventions have led to a heterogeneous mixture of local pride and disengagement with the community and area.

Meadow Well Connected is a charity and community centre on the estate. Established shortly after the unrest to foster community development, it offers a wide range of services around employability, including job coaching, budgeting, and IT training. Community health and well-being being a second core objective, it offers training for people with learning difficulties, alcohol recovery support, cooking classes, exercise groups and an afterschool kids club. Besides the large community centre building, the site also includes five acres of land, partly used as a learning food-growing garden. The organisation has a tradition of partnership work with other charities and institutions through complementary and collaborative services: For example, an independent food bank is using part of their premises.

\subsection{PAR Approach}

PAR is a democratic research approach and methodology that treats participants as competent and reflexive agents. The validity of any knowledge produced depends on whether the resulting action responds to real-life problems and increases community self-determination (Kindon et al., 2007). It thus puts a strong focus on social justice, relationship building, co-construction of knowledge and action, and sees the researcher as part of the field. PAR follows a process of iterative cycles of action and reflection, in which researcher and participants together develop and implement an action plan, reflect upon its implementation, and plan the next cycle (Kindon et al., 2007). This article covers the first three cycles of this PAR collaboration.

While PAR is commonly focused on working with community members, in this particular case the process was initiated by one of the later suppliers of the food hub. A baker and social entrepreneur saw the potential in local food hubs to empower local communities to produce and access good quality food at affordable prices. I, as a researcher, became involved in the project, initially as a facilitator, to bring various stakeholders together, in particular, the community centre. Early on in the project, we decided we wanted to work with an established community-based organisation, as it would already have links with local people. Meadow Well Connected was such an organisation and once the idea had been proposed they decided to collaborate, pilot the idea, and thereafter continue to work with me. While this strong initial focus on the producer-citizen (instead of the consumer-citizen) may seem unusual or even questionable, we argue that a food hub can only be success- ful if it meets the needs of all actors in the supply chain, this includes the supplier's need for viability and in this case the community centre's need to achieve their health and wellbeing goals. The approach and the methods chosen meant that it was possible to work with all food citizens, producers, middle actors, and consumers in this exploratory phase. This being said, the data forming the basis for this article stems primarily from the work conducted with the community organisation and suppliers and as such draws lessons about the challenges of doing food democracy on the ground. As I will discuss later, the partnership has since gone forward based on these lessons with a direct focus on community participation and ownership. The food hub is thus not a solution on its own, but a vehicle to engage local residents and has opened up new action research activities that are beyond the scope of this article.

Acknowledging my own positionality, I as researcher, was also more than just a facilitator and brought my own interests in food democracy and vision of the food hub into the project. My own expertise contributed to shaping it into something that might be different from what commonly would be or has been done in an area such as Meadow Well, e.g., a food bank or a community café. Nevertheless, the food hub development represents a process of negotiation. In each PAR cycle, planning, action, and reflection were carried out collaboratively with equal decision-making power among all participants. Here, the democratic ambitions of food democracy and PAR meet. PAR enables the framing of food democracy as an ongoing negotiation of different ambitions and expertise. The nature of food democracy is therefore not defined by any single participant, and this includes the researcher, but by the product of iterative cycles of action and reflection. (Food) democracy thus becomes the product of a democratic process. Therefore, I argue, along with Hassanein (2003), that a democratic process is the only way to move towards (food) democracy. PAR also allows the process of doing and promoting food democracy in a locally unique way and adapted to specific circumstances. There is no one-size-fits-all approach to food democracy, and following a PAR approach gives participants the tools to develop such a local food democracy.

\subsection{Collaboration Process until Now}

The PAR process in this article covers three cycles of action and reflection. While the division in cycles is useful to make sense of the process, in practice boundaries were fluid and blurry. The first cycle began in May 2017 and lasted about six months, during which the aforementioned baker, the community centre, and I formed the initial partnership and explored the possibility of developing a food hub in Meadow Well. After this period of relationship building, discussing, questioning, and investigating the concept, we collectively agreed on a pilot to test the idea. In this second cycle, a local organic vegetable farm joined the partnership. A butcher and fish- 
monger agreed to supply the food hub, but did not get involved with the partnership beyond that. The food hub thus offered vegetables, bread, meat, and fish. Weekly food orders could be placed via an online shop or in person in the centre. Aggregated orders got submitted to the suppliers once a week, who then delivered in bulk to the community centre. Staff or volunteers bagged customer orders for pick-up from the centre. This setup allowed us to save logistics and delivery costs and to pass on wholesale prices to shoppers. Launched in November 2017, the food hub was initially planned to run for four weeks, but Meadow Well Connected wanted to extend the pilot to allow us to see how it developed over time. After three months, orders began to decline and we decided to stop the pilot to reflect and plan further action. At this point, the baker decided to leave the partnership due to personal differences. During the pilot, I collected data through three methods: 1) field notes from partic- ipant observations and informal conversations with customers and visitors at the centre; 2 ) a cultural probing (Gaver, Dunne, \& Pacenti, 1999) study with eight participants including consumers, organisers, and suppliers; and 3) a reflection workshop with participants from the cultural probing study. The cultural probing package consisted of a custom-built box with four prompt cards, to which participants could either respond in writing, drawing, or by speaking into an audio recorder, which was also supplied in the box (see Figure 1). In the reflection workshop, the field notes, the cultural probing, as well as the workshop participants' experiences shared in the workshop were drawn together and discussed collectively, resulting in the creation of a vision of a future Meadow Well food hub that builds on the lessons learned from the pilot (see Figure 2).

In the third cycle, we first engaged in planning to relaunch the food hub. The two key insights from the pilot

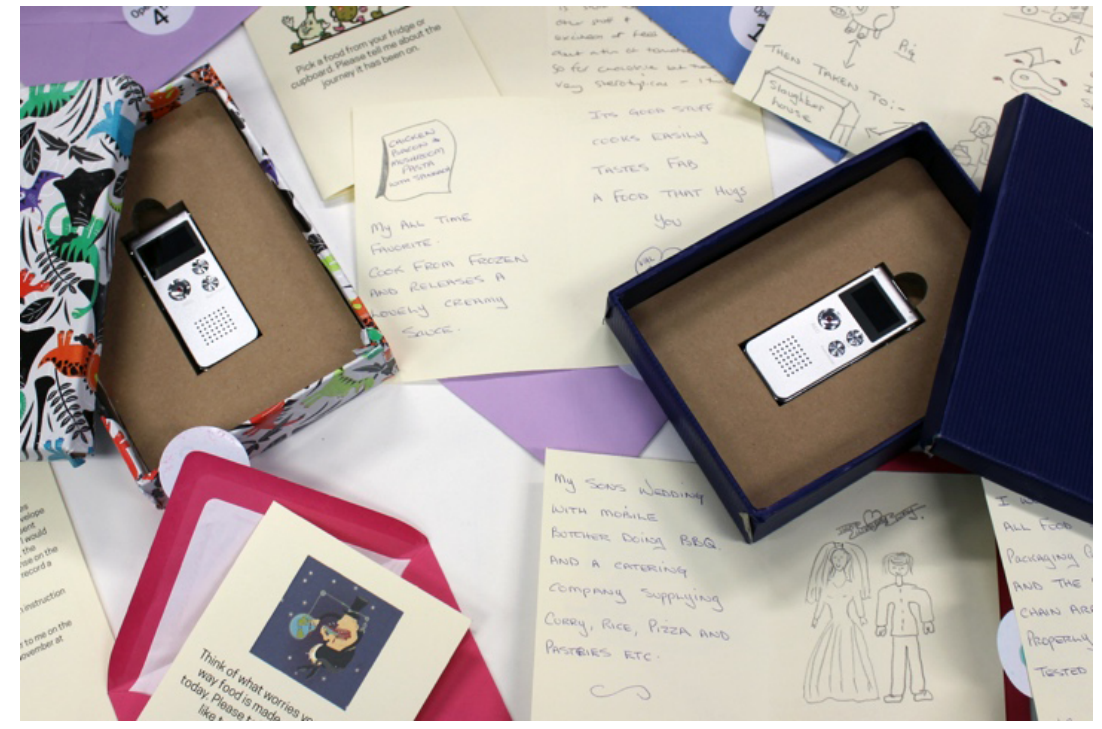

Figure 1. Cultural probing packages with boxes, filled in prompt-cards, and audio recorders.

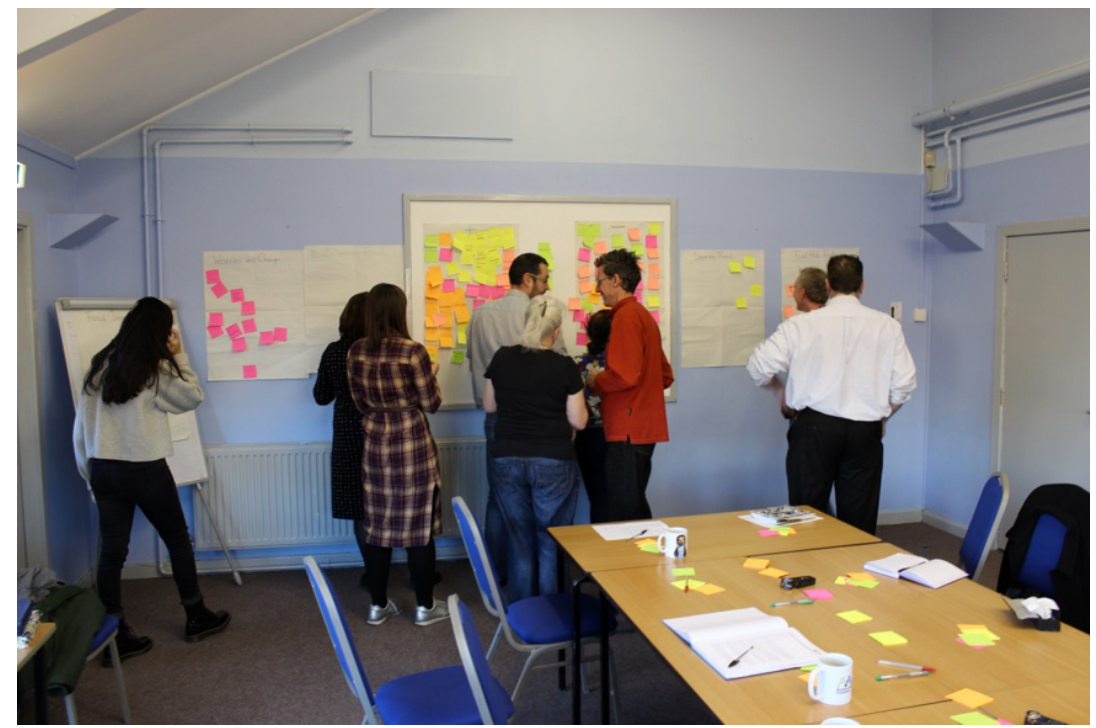

Figure 2. Participants in the reflection workshop discussing food hub feedback written on post-it notes. 
were the need for direct community engagement and a better food hub identity. These insights led to two distinct activities carried out with Meadow Well Connected: first, a series of three co-design workshops to develop community engagement activities (see Figure 3); second, a workshop and subsequent collaborative process to find a new name, logo, and value statement for the food hub. In parallel, we engaged in negotiations with new food producers to join the partnership and supply the food hub. These activities resulted in the food hub relaunching in November 2018 with more professional branding, streamlined logistics processes, and a partly new set of four suppliers, offering vegetables, bread, mushrooms, and meat. So far, the food hub has attracted about 50 unique customers (one-off or repeat) and is trading on average above $£ 100$ per week.

In this article I draw on field notes from participant observation and informal chats at the centre, meeting minutes, e-mails, and the data from the cultural probing and all workshops, spanning all three cycles. I analysed the data using thematic analysis (Braun \& Clarke, 2006), identifying three key themes from patterns of codes. The next section will unpack these themes, providing insights into how the food hub responded to and worked with the challenges facing CFNs identified earlier.

\section{Findings: CFN Tactics in the Context of Socio-Economic Deprivation}

In presenting the findings from the PAR process outlined above, this section serves two purposes. First, it demonstrates how the challenges of ethics, participation, and system transformation played out in the case of the Meadow Well food hub. Second, it identifies the creative tactics of a CFN working in a deprived area to navigate these challenges. Using the challenges as an analytical lens, the three themes presented in this section thus cover tactics to: 1) balance ethics of environmental sustainability, social justice, and health; 2) configure accessible participation; and 3) build collaborations for wider impact.

\subsection{Tactics to Balance Ethics of Sustainability, Social Justice and Health}

Meadow Well Connected was initially very sceptical of the proposal to work on a local food hub. There was an assumption that in the area people would always go for the cheapest food. This was, however, contradicted with the assumption that people often went for the most convenient option-ready-meals and take-aways-which are more expensive than cooking from scratch. With the aim of challenging the price barrier of middle-class food hubs, the model chosen allowed pre-ordered food to be delivered in bulk at wholesale or discounted prices, without adding any margins. Nevertheless, the partners had to acknowledge that, by providing mostly organic, local, and healthy produce, the food was more expensive than cheap (and low quality) alternatives in the supermarket. Meadow Well Connected, therefore, wanted to communicate the better value for money. For example, early on in the process, the group decided to introduce 'meal boxes,' packages that included a recipe card and the ingredients needed to cook at home. This should not only make it easier for less confident cooks to give it a try, but the meal boxes also served as demonstrators to show that the cost per serving can be as little as $f 1$ when cooking from scratch. Integrating these meals into the cooking classes and selling them cooked in the centre's café should also showcase how tasty and filling the food is.

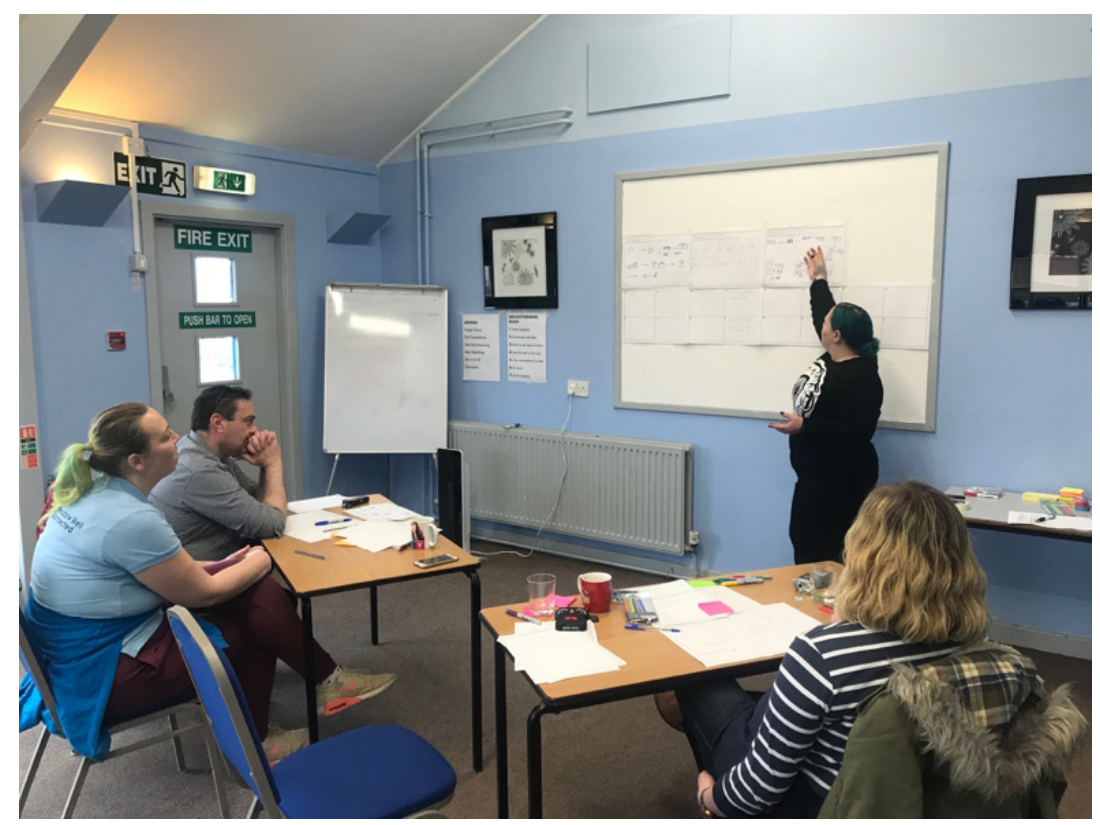

Figure 3. A participant in one of the community engagement co-design workshops explains an idea to the group. 
As a customer puts it in the reflection workshop:

But we found, my partner and $\mathrm{I}$, that this is a bit more than I would normally pay, but we'll give it a go. But we found we didn't need as much because it was much more filling. So, it was value for money. You got more for your money at the end of the day because you could freeze what you hadn't used. (Food hub customer)

Accompanying this, the notion of 'local' which the food hub wanted to communicate was less concerned with food miles, but rather with accommodating for local taste. Similarly, Meadow Well Connected decided to downplay health and sustainability aspects of the food, because this is associated with 'posh' (and expensive) food and might deter people from buying.

\subsection{Tactics to Configure Accessible Community Participation}

The negotiation and questioning of what the food hub is supposed to be is an ongoing process that has been discussed throughout all PAR cycles. It generally varies between being an operation that primarily targets wealthier customers who thus support the community indirectly and a community-owned, independent organisation that benefits the local population directly. Mirroring this, a tension exists between professionalism (ensuring a smooth customer experience) and revealing some of the complexities of a food hub in its early stages and the wider food supply chain. This includes, for example, discomfort with break-downs, such as lack of product availability or technical issues with the online shop. My field notes from a discussion about this with members of staff illustrate such a moment drastically:

This week was the second time that [the fruit and vegetable supplier] could not deliver oranges and kiwis. The oranges were ordered by a new customer, so [a member of staff] decided to quickly buy some at [a supermarket] to replace the missing items without telling the customer. [Another member of staff] later said especially for new customers they want to provide the best customer experience, they want to look professional and deliver on the promise. I argued that it was not very honest, and we should rather tell them that we can't deliver and offer a refund. But we decided that [the farmer] needs to update his stock [in the online shop] if he can't deliver. (Author's field notes, 24 January 2019)

I want to argue that this reaction does not represent a lack of sense for transparency, but was an act of panic during a process of learning what it means to run a food hub in contrast to, for example, a supermarket with permanent product availability. Meadow Well Connected has not repeated this reaction since and is now transparently informing customers when products cannot be delivered. That being said, the case does illustrate their strong views on how the food hub needs to be accessible for all: Given the complex lives and everyday challenges of the local population, Meadow Well Connected argued that it cannot count on engaged individuals with a high level of 'tolerance' for inefficiencies and break-downs, something that is usually common among early adaptors in processes of social innovation (Manzini, 2015). Participation in the food hub, therefore, needs to be as accessible as possible, allowing for different levels or forms of participation. Through continuous negotiations, the PAR process has begun to introduce more community-based participation. For example, initial approaches to promote and expand the food hub included standard marketing (e.g., leaflets, posters, social media posts) and educational approaches (cooking classes, tasters, sale of cooked meals in the café). Based on the three co-design workshops, we are now recruiting local people into the partnership to co-design a series of engagement activities and eventually to run and steer the food hub. Plans are at an early stage and so far, include food hub 'champions' and various food-related activities that offer social spaces to connect (e.g., a supper club, a baking group, visits to producers).

\subsection{Tactics to Build Collaborations for Wider Impact}

The community centre has a tradition of collaborative work, to the extent that it hosts several other charities and companies who offer complementary services in the same building. Leveraging these existing links from the start, Meadow Well Connected focused on developing activities through which other organisations' support for the food hub would be mutually beneficial. A member of staff makes this explicit in one of the codesign workshops:

Well, when it comes to partnership working there's got to be something in it for the other organisation. Whether it's just demonstrating that they're working with another organisation or whether they're looking for statistics or have got a particular interest in the programme or project that we're doing. (Member of staff, Meadow Well Connected)

So far, corporate partners of the centre buy food from the food hub as part of their corporate social responsibility strategy. We also established several new links to the university, for example through having students working on a marketing strategy while they get credits for a career development module. The group is also in dialogue with a local school to devise activities for critical engagement of children with food and the food system, while at the same time promoting the food hub. Moreover, the group is considering activities that could be run in collaboration with the local authority, contributing to its public health policy goals, as well as other third sector or- 
ganisations, such as a mental health and an older people's charity. Finally, the group has also successfully leveraged connections to the local branch of the public service broadcaster to produce a radio and online feature about the food hub and its aims. Collaboration also includes working better with existing projects or services offered by Meadow Well Connected directly. The food hub so far provides food for cooking courses and cooked meals in the café. Conversely, the food hub provided the platform for selling produce from the centre's gardens. For each order above $£ 10$, the food hub also donates a box of fresh vegetables to the co-located food bank. Most recently, a group of people attending an alcohol 'recovery café' in the centre started becoming involved in co-designing food-related activities that connect with the food hub.

\section{Discussion: PAR and a Plurality of Localised Food Democracies}

The specific approach taken for the Meadow Well food hub illustrates both how the challenges of CFNs to work towards a food democracy for all, i.e., ethics, participation, and system transformation, can play out and what local tactics as responses to them might be deployed. In the presented case tactics included an attempt to flexibly balance ethically sourced food (environmentally, healthy, and just for producer-citizens) with an offer that is just for consumer-citizens (affordable food with a local taste) and to communicate this value of food. Tactics in regard to participation comprise actions to configure participation in an accessible way given limited resources. Finally, possibly as a way to support the first two, tactics for transformation involve building collaborations with complementary external organisations and within the community centre. Using this set of tactics, the partnership has overcome some of the early challenges of starting a CFN, and especially those exacerbated by working in a deprived neighbourhood. This is, however, not to say that the tactics will prove to be successful in the long run. In this section, I reflect on the tactics that were made visible through the PAR process of developing and launching this CFN in the form of a food hub. I also relate them to the corresponding elements of food democracy-ethics, participation, and system transformation-and how our theoretical framing of food democracy can be sharpened.

\subsection{Ethics of Food Democracy: From Balancing Everything to Community Sensitivity}

One of CFNs' central challenges is to balance different ethical dimensions of food democracy to avoid producing a two-tier system of ethical consumerism that renders healthy and sustainable food expensive (Levkoe, 2011) or turns CFNs into 'civilising' and moralising missions in which outsiders bring 'good food' into poor communities (Guthman, 2008a). While Meadow Well is a predomi- nantly white British estate, high levels of socio-economic deprivation mean the food typically produced by CFNs would not be affordable for its working-class population. The food bank just next door to Meadow Well Connected is a visual reminder of this. As with many CFNs, the Meadow Well food hub thus has to balance social justice goals and economic viability, as it operates within a persisting neoliberal system of injustices: It has to compete with low prices of low-quality supermarket food, produced through global exploitative food chains. And it also has to grapple with oppressed people locally, who cannot afford better quality food and might feel too disengaged to care. While food sold via the Meadow Well food hub costs less than food of comparable quality in supermarkets, it is still more expensive than cheap alternatives. Nevertheless, since shopping practices indicate that people do not always go for the cheapest, but also for the nearest and most convenient options which carry higher prices, the food hub's pricing structure becomes more attractive again.

The initial negotiations between researchers and centre staff illustrate their doubts over the local food hub model. The fact that they still decided to join the partnership puts the community centre as an actor in an interesting position. Having been established in the community for 25 years, are they insiders or outsiders? Are they, following their health and well-being agenda, bringing good food to others, or to their own community? There is no easy answer to these questions. Either way, the community centre's aims and approach mean they are not in the position to directly work on structural change, e.g., by advocating for policy change. Instead, a food hub developed based on their sensitivity to the local community, who would otherwise have been alienated, becomes an interesting and viable route to explore. Far from being a solution, aspects like downplaying 'healthy' and 'organic' food and communicating it as 'tasty' and 'local' (as in community-level local) become a creative tactic to do things differently. As such, the food hub is both the local and unique outcome of a PAR collaboration situated in a specific site, aiming to address real-world problems of communities, as well as a reflection of a reality in which small and local charities cannot address the systemic root causes of poverty and diet-related problems. The food hub, therefore, needs to be evaluated in regards to its practical and specific possibilities. Following a flexible PAR approach allowed the development of a CFN shaped by this practicality and specificity. While one might criticise that this outcome does not necessarily constitute food democracy as conceived theoretically and ideally, we argue that by understanding food democracy as a plurality of processes and approaches, this shifts the question to one of where and how to locate a food democracy. Building on Hassanein's (2003) argument of incremental change through compromise, we then see many localised food democracies with varying characteristics and development routes. 


\subsection{Participation in Food Democracy: From Skills to Relationships}

The second challenge of CFNs is the need for skills to be able to participate. The Meadow Well food hub has clearly faced this challenge. Following a PAR approach, the partnership has been democratically run in all phases, including initial discussions, conceptualisation, planning, realisation, evaluation, and relaunch of the food hub. Evaluation data were discussed with participants and decision-making on how to continue in each phase was collective, strongly driven by participants. Collective knowledge production aimed primarily on actionable results, reflecting the overall values of PAR (Kindon et al., 2007; McIntyre, 2008). However, as discussed in Section 3.2, in this exploratory phase the partnership was not able to include many local residents or customers of the food hub in participatory activities. Meadow Well Connected generally attributes this to the different priorities of people with complex lives. Equally, the emphasis on building organisational collaborations with the private, public, and third sector meant there was little contact with the potential users of the food hub as such. The low involvement of citizens reflects the challenges of co-designing responses to real-world problems in an area that has seen many short-lived community engagement interventions coming and going over time, leaving many locals relatively disengaged.

This allows for two reflections on food democracy and PAR. For food democracy, this means that skills development (food skills or civic skills) becomes secondary, but that the process of building a CFN begins also where any PAR process begins: by building relationships and trust. While in the first two years of this process, much focus has been on relationship-building with supplier-citizens and middle-actor-citizens, taking this action-research forward, the focus is now shifting to relationship-building with consumer-citizens. The community engagement activities currently being planned do not have an educational but a relational character (Mclvor \& Hale, 2015). Conversely, for PAR this means going back to its roots as 'engaged pedagogy' (Kindon et al., 2007). The researcher becomes more than just a facilitator, in that they become a resource and capacity, bringing in expertise and new ideas for social innovation. In the spirit of PAR, this 'expert' knowledge enters a dialogue with local expert knowledge held by participants. This does, on the other hand, raise questions about reliance and long-term sustainability. The process can, however, be a trigger and starting point for the formation of engaged publics (Mouffe, 2000). In this way, PAR becomes an enabling approach to collaboratively build a CFN in a context of socio-economic deprivation and exclusion. For food democracy, this means that CFNs are less of a formal 'schoolhouse' for democracy (Levkoe, 2006), but more like an informal get-together, again being made up of many localised differentiations of food democracies.

\subsection{Transformation towards Food Democracy: From Scaling Up to Collaborations and Networks}

Facing a global food system that continues to be unsustainable and unjust, how can a small initiative in Meadow Well be a driver of food system democratisation? Conversely, how can a food hub, in the spirit PAR and its focus on responses to improve people's everyday life, focus on the root causes of food injustices (Guthman, 2011) without losing its human scale? Drawing on social innovation, I argue that networks are a possible way to remain small and local, while at the same time being open and connected (Manzini, 2015). While Meadow Well food hub is an experiment in its early stages, if successful it can consolidate and become a model to be propagated, replicated, and adapted to new contexts. Indeed, the Meadow Well food hub in itself is a local adaptation of the food hub model experimented with and consolidated nationally and globally. While each replication is different, it moves the same idea along and diffuses it, contributing to the diversity and heterogeneity of localised food democracies. We can see the first steps to such a network with Meadow Well linking the food hub with other organisations by finding mutually beneficial action. Research can play a critical role in supporting this process by creating toolkits to support non-expert communities in recognising and applying a collaborative response locally (and by this moving the overall idea of food democracy along). As such, Meadow Well, while not impacting the global food system on its own, can be seen as part of a network that implements, replicates, and connects ideas and agents of food democracy. As such, the question of the impact of small, local, or niche initiatives on the larger food system becomes less important. Instead, we can ask about the local impact and how this connects with other local initiatives elsewhere. Again, framing food democracy as a plurality can help to recognise this contribution of small initiatives to an incremental and heterogenous transformation of the food system. PAR and its approach of enabling local communities to improve their living conditions is again suited to facilitate such a plurality of transformative processes.

\section{Conclusion}

This article provided an empirical account of an earlystage CFN that aims to improve food access in a deprived neighbourhood. The specificities of the location illustrate the challenges of ethics, participation, and system transformation that CFNs must consider if they are to work towards a food democracy for all, or rather a plurality of localised food democracies. Based on the experiences in developing the Meadow Well food hub, I propose such a localised and differentiated understanding of food democracy. Accordingly, addressing the challenge of balancing environmental sustainability, social justice, and community and individual health, I presented tactics of flexibly realising and communicating value for money 
and ethical standards. To address the challenge of either requiring skills to participate in a CFN or focusing on their development, the community centre is sensitive to offer accessible participation and is currently developing community engagement activities that focus on relationship building rather than skills. Finally, the local and specific development of the Meadow Well food hub helps to reframe the challenge for CFNs in achieving wider system transformation beyond niche solutions, to one of how to achieve local impact and connect with other initiatives or organisations to replicate success elsewhere.

As already indicated, this ongoing PAR process is currently developing action to explicitly recruit Meadow Well residents into the partnership. This includes codesigning food-related activities with community members that they deem interesting and beneficial. While activities might simply be a fun way to socialise over food, they might also address immediate needs (such as accessing cheap food) or self-development plans (such as learning how to cook or to start a food business). This process will certainly change what the food hub is, but the fact that it is already going on and is not just a future possibility provides a very tangible and real hook to talk about and imagine future food-related developments. As such, the initial focus on suppliers getting the food hub up and running was not a solution for its own sake, but also a conversation starter for community engagement in a complex setting. In parallel, the food hub is continuing to build networks with other organisations, including corporate partners, a hands-on learning programme with a local school, and engaging in knowledge exchange with other food hubs and national networks.

PAR's democratic and localised approach aiming at addressing real-world problems and improving community self-determination stands out as uniquely suited to help navigating the ethical challenges CFNs face. A process that treats participants as competent agents with local expertise can produce context-sensitive, coconstructed action and knowledge. Researchers as engaged participants can play an important role in triggering, resourcing, and disseminating such initiatives by bringing in their own experiences and expertise. Framing food democracy as a plurality to build and replicate local CFNs, aligns with PAR's own democratic ambitions to enable local innovation.

\section{Acknowledgments}

We thank our partners for enabling this research. In particular, we want to thank Graham Bone, Leah O'Sullivan, Sarah McDonald, and Mandi Cresswell from Meadow Well Connected for their support and collaboration. This research was funded through the EPSRC Centre for Doctoral Training in Digital Civics (EP/L016176/1). Data supporting this publication is not openly available due to confidentiality considerations. Additional metadata are available at https://doi.org/10.25405/data.ncl.8943476.

\section{Conflict of Interests}

The author declares no conflict of interests.

\section{References}

Allen, P. (2008). Mining for justice in the food system: Perceptions, practices, and possibilities. Agriculture and Human Values, 25(2), 157-161. https://doi.org/ 10.1007/s10460-008-9120-6

Born, B., \& Purcell, M. (2006). Avoiding the local trap. Journal of Planning Education and Research, 26(2), 195-207. https://doi.org/10.1177/ 0739456X06291389

Bornemann, B., \& Weiland, S. (2019). Empowering people: Democratising the food system? Exploring the democratic potential of food-related empowerment forms. Politics and Governance, 7(4), 105-118. https://doi.org/10.17645/pag.v7i4.2190

Bos, E., \& Owen, L. (2016). Virtual reconnection: The online spaces of alternative food networks in England. Journal of Rural Studies, 45(March), 1-14. https:// doi.org/10.1016/j.jrurstud.2016.02.016

Bradley, K., \& Herrera, H. (2016). Decolonizing food justice: Naming, resisting, and researching colonizing forces in the movement. Antipode, 48(1), 97-114. https://doi.org/10.1111/anti.12165

Braun, V., \& Clarke, V. (2006). Using thematic analysis in psychology. Qualitative Research in Psychology, 3(2), 77-101. https://doi.org/10.1191/ 1478088706qp063oa

Carolan, M. (2017). More-than-active food citizens: A longitudinal and comparative study of alternative and conventional eaters. Rural Sociology, 82(2), 197-225. https://doi.org/10.1111/ruso.12120

Connelly, S., Markey, S., \& Roseland, M. (2011). Bridging sustainability and the social economy: Achieving community transformation through local food initiatives. Critical Social Policy, 31(2), 308-324. https:// doi.org/10.1177/0261018310396040

Davenport, S. G., \& Mishtal, J. (2019). Whose sustainability? An analysis of a community farming program's food justice and environmental sustainability agenda. Culture, Agriculture, Food and Environment, 41(1), 56-65. https://doi.org/10.1111/cuag.12227

de Certeau, M., Giard, L., \& Mayol, P. (1998). The practice of everyday life. Volume 2: Living \& cooking. Minneapolis, MN: University of Minnesota Press.

Fischer, M., Pirog, R., \& Hamm, M. W. (2015). Food hubs: Definitions, expectations, and realities. Journal of Hunger \& Environmental Nutrition, 10(1), 92-99. https://doi.org/10.1080/19320248.2015.1004215

Gaver, B., Dunne, T., \& Pacenti, E. (1999). Design: Cultural probes. Interactions, 6(1), 21-29. https://doi.org/10. $1145 / 291224.291235$

Gómez-Benito, C., \& Lozano, C. (2014). Constructing food citizenship: Theoretical premises and social practices. Italian Sociological Review, 4(2), 135-156. https:// 
doi.org/10.13136/isr.v4i2.79

Guthman, J. (2008a). Bringing good food to others: Investigating the subjects of alternative food practice. Cultural Geographies, 15(4), 431-447. https://doi.org/ $10.1177 / 1474474008094315$

Guthman, J. (2008b). "If they only knew": Color blindness and universalism in California alternative food institutions. The Professional Geographer, 60(3), 387-397. https://doi.org/10.1080/00330120802013679

Guthman, J. (2011). Weighing in: Obesity, food justice, and the limits of capitalism. Berkeley, CA: University of California Press.

Hassanein, N. (2003). Practicing food democracy: A pragmatic politics of transformation. Journal of $R u$ ral Studies, 19(1), 77-86. https://doi.org/10.1016/ S0743-0167(02)00041-4

Kindon, S. L., Pain, R., \& Kesby, M. (Eds.). (2007). Participatory action research approaches and methods: Connecting people, participation and place. London: Routledge.

Kneafsey, M., Owen, L., Bos, E., Broughton, K., \& Lennartsson, M. (2017). Capacity building for food justice in England: The contribution of charityled community food initiatives. Local Environment, 22(5), 621-634. https://doi.org/10.1080/13549839. 2016.1245717

Lang, T. (2007). Food security or food democracy? Pesticides News, 78, 12-16.

Levkoe, C. Z. (2006). Learning democracy through food justice movements. Agriculture and Human Values, 23(1), 89-98. https://doi.org/10.1007/s10460-0055871-5

Levkoe, C. Z. (2011). Towards a transformative food politics. Local Environment, 16(7), 687-705. https://doi. org/10.1080/13549839.2011.592182

Levkoe, C. Z., Hammelman, C., Craven, L., Dandy, G., Farbman, J., Harrison, J., \& Mount, P. (2018). Building sustainable food systems through food hubs: Practitioner and academic perspectives. Journal of Agriculture, Food Systems, and Community Development, 8(2), 107-122. https://doi.org/10.5304/jafscd.2018. 082.008

Lohest, F., Bauler, T., Sureau, S., Mol, J. Van, \& Achten, W. (2019). Linking food democracy and sustainability on the ground: Learnings from the study of three alternative food networks in Brussels. Politics and Governance, 7(4), 21-31. https://doi.org/10.17645/ pag.v7i4.2023

Lorenzini, J. (2019). Food activism and citizens' democratic engagements: What can we learn from marketbased political participation? Politics and Governance, 7(4), 131-141. https://doi.org/10.17645/pag. v7i4.2072

Lyson, T. A. (2012). Civic agriculture: Reconnecting farm, food, and community. Medford, MA: Tufts University Press.

Manzini, E. (2015). Design, when everybody designs: An introduction to design for social innovation. Cam- bridge, MA: MIT Press.

Mares, T. M., \& Alkon, A. H. (2011). Mapping the food movement: Addressing inequality and neoliberalism. Environment and Society, 2(1), 68-86. https://doi. org/10.3167/ares.2011.020105

McGlone, P., Dobson, B., Dowler, E., \& Nelson, M. (1999). Food projects and how they work. York: YPS for the Joseph Rowntree Foundation.

Mclntyre, A. (2008). Participatory action research. Los Angeles, CA: Sage.

Mclvor, D. W., \& Hale, J. (2015). Urban agriculture and the prospects for deep democracy. Agriculture and Human Values, 32(4), 727-741. https://doi.org/10. 1007/s10460-015-9588-9

Moragues-Faus, A., \& Marsden, T. (2017). The political ecology of food: Carving 'spaces of possibility' in a new research agenda. Journal of Rural Studies, 55, 275-288. https://doi.org/10.1016/j.jrurstud. 2017.08.016

Mouffe, C. (2000). Deliberative democracy or agonistic pluralism? Political Science Series, 72, 1-17. https:// doi.org/10.2307/40971349

OpenDataCommunities. (2015). Indices of deprivation 2015 explorer. Department for Communities and Local Government. Retrieved from http://dclgapps. communities.gov.uk/imd/idmap.html

Perrett, A., \& Jackson, C. (2015). Local food, food democracy, and food hubs. Journal of Agriculture, Food Systems and Community Development, 6(1), 7-18. https://doi.org/10.5304/jafscd.2015.061.003

Renting, H., Schermer, M., \& Rossi, A. (2012). Building food democracy: Exploring civic food networks and newly emerging forms of food citizenship. International Journal of Sociology of Agriculture and Food, 19(3), 289-307.

Stroink, M. L., \& Nelson, C. H. (2013). Complexity and food hubs: Five case studies from Northern Ontario. Local Environment, 18(5), 620-635. https://doi.org/ 10.1080/13549839.2013.798635

Tornaghi, C. (2017). Urban agriculture in the fooddisabling city: (Re)defining urban food justice, reimagining a politics of empowerment. Antipode, 49(3), 781-801. https://doi.org/10.1111/anti.12291

Vines, J., Clarke, R., Wright, P., McCarthy, J., \& Olivier, P. (2013). Configuring participation: On how we involve people in design. In Proceedings of the SIGCHI Conference on Human Factors in Computing Systems-CHI '13 (pp. 429-438). New York, NY: ACM Press. https://doi.org/10.1145/2470654.2470716

Werkheiser, I., \& Noll, S. (2014). From food justice to a tool of the status quo: Three sub-movements within local food. Journal of Agricultural and Environmental Ethics, 27(2), 201-210. https://doi.org/10.1007/ s10806-013-9459-6

Zitcer, A. (2015). Food co-ops and the paradox of exclusivity. Antipode, 47(3), 812-828. https://doi.org/10. 1111/anti.12129 


\section{About the Author}

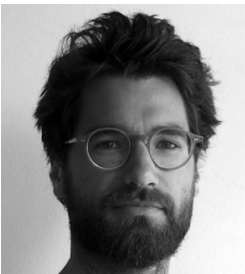

Sebastian Prost holds a master's degree in Human-Computer Interaction from the Vienna University of Technology, Austria and a master's in Digital Civics from Newcastle University, UK. Currently, he is a PhD Researcher at Newcastle University's Open Lab at the School of Architecture, Planning and Landscape. He has co-authored several peer-reviewed articles intersecting the fields of human geography, sociology, and design. In his PhD, he researches food democracy, alternative food networks, food justice, and social innovation. 